\title{
The inverse association between ANGPTL8 and PI3K- mTOR-PPARy expressions in adipose tissue of high- fructose-fed rats: The modulatory effect of kefir
}

\author{
Fatma Akar ${ }^{1}$ (D), Ceren Güney ${ }^{1}$ (D), Hamdi Barbaros Özer² (D), Mehmet Bilgehan Pektaș ${ }^{3}$ (D), \\ Halit Buğra Koca ${ }^{4}$ (D) Aytaç Kocabaș ${ }^{5}$ (D), Gökhan Sadi ${ }^{5}$ (1) \\ ${ }^{1}$ Gazi University, Faculty of Pharmacy, Department of Pharmacology, Ankara, Turkey \\ ${ }^{2}$ Ankara University, Faculty of Agriculture, Department of Dairy Technology, Ankara, Turkey \\ ${ }^{3}$ Afyonkarahisar Health Sciences University, Faculty of Medicine, Department of Medical Pharmacology, Afyonkarahisar, \\ Turkey \\ ${ }^{4}$ Afyonkarahisar Health Sciences University, Faculty of Medicine, Department of Medical Biochemistry, Afyonkarahisar, \\ Turkey \\ ${ }^{5}$ Karamanoğlu Mehmetbey University, K.Ö. Science Faculty, Department of Biology, Karaman, Turkey
}

ORCID IDs of the authors: F.A. 0000-0002-5432-0304; C.G. 0000-0002-3267-2886; H.B.Ö. 0000-0001-6669-0444;

M.B.P. 0000-0003-0055-7688; H.B.K. 0000-0002-5353-3228; A.K. 0000-0001-7622-1932; G.S. 0000-0002-6422-1203

Cite this article as: Akar, F., Guney, C., Ozer, H. B., Pektas, M. B., Koca, H. B., Kocabas, A., \& Sadi, G. (2021). The inverse association between ANGPTL8 and PI3K-mTOR-PPARy expressions in adipose tissue of high-fructose-fed rats: The modulatory effect of kefir. istanbul Journal of Pharmacy, 51 (3), 299-306.

\begin{abstract}
Background and Aims: The dietary high-fructose intake might be a risk factor for several metabolic diseases. Kefir, a fermented milk product, has been proposed to have beneficial health effects. In this study, we aimed to investigate the effects of fructose consumption and kefir supplementation on the lipogenesis-related genes including angiopoietin-like protein 8 (angptl8), phosphoinositide 3-kinase (pi3k), mammalian target of rapamycin (mtor), and peroxisome proliferator-activated receptor $\gamma$ (ppary) as well as inflammatory factors in the adipose tissue to provide new mechanistic insights into lipogenesis. Methods: Fructose was given to the rats as a $20 \%$ solution in drinking water for 15 weeks. Kefir was administered by gastric gavage once a day during the final six weeks.

Results: There was an upregulation of angptl8 mRNA expression in adipose tissue of rats given fructose. However, expressions of pi3k, mtor, and ppary mRNAs were impaired in the adipose tissue. The increased interleukin (IL) $-1 \beta$ levels, but decreased IL-10, were also measured. There was no change in expressions of sirtuin1 (sirt1) and nuclear factor erythroid 2-related factor 2 ( $n r f 2$ ). Kefir supplementation suppressed expression of angptl8, but increased pi3k and mtor in the adipose tissue of high-fructose-fed rats.

Conclusion: Activation of gene expression of angptl8, together with the suppression of pi3k, mtor, and ppary, showed that there was an inverse association between these lipogenic genes in the adipose tissue of rats fed with high-fructose. Kefir supplementation has modulatory effects on fructose-induced changes except for ppary expression. These findings showed that dietary fructose and kefir might reciprocally affect the lipogenesis-related genes in the adipose tissue.
\end{abstract}

Keywords: Dietary fructose, Kefir, ANGPTL8, PI3K-mTOR-PPARy pathway, Lipogenesis

Address for Correspondence:

Fatma AKAR, e-mail: fakar@gazi.edu.tr

This work is licensed under a Creative Commons Attribution 4.0 International License. 


\section{INTRODUCTION}

The metabolic syndrome is a cluster of conditions including hyperlipidemia, hyperinsulinemia, hypertension, central adiposity, fatty liver disease, and chronic low-grade inflammation. The increased prevalence of metabolic syndrome in the world might be due to high consumption of fructose, particularly in the form of soft drinks, in the current human diet (Hannou, Haslam, McKeown, \& Herman, 2018; Jensen et al., 2018). We have previously shown that dietary high-fructose leads to a change in adipose tissue function with an alteration in insulin signaling, activation in inflammatory cytokines, and upregulation in lipogenic genes (Pektas, Koca, Sadi, \& Akar, 2016; Akar, Sumlu, Alçı̆̆ır, Bostancı, \& Sadi, 2021). Besides, we have determined that high-fructose-induced metabolic disturbance is more likely related to abdominal fat accumulation, but independent from general obesity (Pektaş, Sadi, \& Akar, 2015; Akar et al., 2021). Previously, it was shown that the expansion of white adipose tissue was related to insulin resistance and low-grade inflammation (Bastard et al., 2006). Adipose tissue has endocrine and metabolic functions by secreting several hormones and factors that influence lipid and glucose metabolism as well as the effectiveness of insulin (Scherer, 2006). Therefore, dysfunction of adipose tissue might be associated with metabolic diseases.

Angiopoietin-like proteins (ANGPTLs) have been proposed to play essential roles in lipoprotein metabolism, adipogenesis, and inflammation (Carbone et al., 2018). ANGPTL8, also known as lipasin, refeeding induced fat and liver (RIFL) and betatrophin, is mainly expressed in the liver and adipose tissue (Ren, Kim, \& Smas, 2012; Zhang, 2012; Wang et al., 2013). Previously, ANGPTL8 was found to regulate plasma triglyceride levels by inhibiting lipoprotein lipase, a key enzyme in the lipoprotein lipolysis pathway (Quagliarini et al., 2012). Deletion of the angpt/8 gene in mice was shown to reduce plasma triglyceride levels (Ren et al., 2012; Quagliarini et al., 2012). On the contrary, overexpression of ANGPTL8 causes an increase in plasma triglyceride levels in mice (Quagliarini et al., 2012; Zhang, 2012). Moreover, in type 2 diabetic patients with insulin resistance, ANGPTL8 levels were positively correlated with triglyceride levels (Chen, Susanto, Chuang, Liu, \& Wang, 2016). Metabolic effects of insulin including adipogenesis and lipid accumulation are mediated by phosphoinositide 3-kinase (PI3K)- protein kinase B (Akt) pathway (Wang \& Sul 1998; Sakaue et al., 1998). PI3K-Akt pathway was damaged in obesity and type 2 diabetes resulting in insulin resistance (Huang, Liu, Guo, \& Su, 2018). Additionally, the stimulatory effect of insulin on lipid metabolism and deposition was mediated by PI3K-Akt-mammalian target of rapamycin (mTOR) (Han et al., 2015). Indeed, mTOR is involved in the regulation of adipogenesis, lipid, and glucose metabolism, as well as insulin resistance (Laplante \& Sabatini, 2012). The mTOR complex, mTORC1, increases the expression of peroxisome proliferator-activated receptor $\gamma$ (PPAR $\gamma$ ), which is the master transcriptional regulator of adipocyte differentiation and lipid storage (Zhang et al., 2009). Moreover, mTOR deficiency was found to cause insulin resistance and downregulation of PPARy expression in white adipose tissue of mice (Shan et al., 2016). The relationship between ANGPTL8 and
PI3K-mTOR-PPARY pathway in adipose tissue is not understood. Therefore, in this study, the association between these lipogenic genes was examined for the first time in the fat tissue of high-fructose-fed rats.

Kefir, a fermented milk product, contains several lactic acid and acetic acid bacteria in a polysaccharide matrix (Rosa et al., 2017). Kefir consumption was reported to have beneficial effects in several disease models (Kim, Jeong, Kim, \& Seo, 2019). Kefir peptides were shown to reduce hepatic lipid accumulation and inflammation in high-fructose-fed mice (Chen et al., 2016). Besides, Lactobacillus kefiri (L. kefiri), a kefir bacterium, reduced epididymal adipose tissue expansion and inflammatory factors in fructose-rich diet-fed mice (Zubiría et al., 2017). In another study, kefir grain powder was shown to suppress the lipid synthesis and inflammatory cytokines in adipose tissue and liver of diet-induced obese mice (Choi et al., 2017). In a very recent study, we showed that kefir supplementation improved the level of plasma triglyceride, hepatic weight, triglyceride content, and fatty degeneration as well as omental fat accumulation in high-fructose-fed rats. Moreover, kefir supplementation reduced expression of lipogenic genes, sterol regulatory element-binding protein (srebp)-1c and fatty acid synthase (fasn), as well as produced a marked downregulation in tumor necrosis factor-alpha (TNF-a) and nuclear factor-kappa $\mathrm{B}$ (NF-KB) expressions in the liver, but not in adipose tissue of high-fructose-fed rats (Akar et al., 2021). Tibet kefir milk administration reduced serum triglyceride and abdominal fat mass together with an upregulation of the angpt/4 gene in fat tissue of high-fat diet-fed rats (Gao et al., 2019). Modulation of ANGPTL8 and PI3K-mTOR-PPARY pathway in adipose tissue by kefir remains to be investigated. In the present study, we have examined the impacts of dietary fructose and kefir supplementation on gene expressions of angpt/8 and PI3K-mTORPPARy pathway elements, as well as the levels of inflammatory cytokines in the adipose tissue of rats in order to provide new mechanistic insights into lipogenesis.

\section{MATERIALS AND METHODS}

\section{Animals and diets}

The Ethical Animal Research Committee of Gazi University (G.Ü.ET-18.018) approved the protocol for animal usage. Threeweek-old male Wistar rats were housed in temperature- and humidity-controlled rooms (at $20-22^{\circ} \mathrm{C}$ and $40-60 \%$ humidity), with a 12-h light-dark cycle. The rats were fed with a standard rodent chow diet composed of $62 \%$ starch, $23 \%$ protein, $4 \%$ fat, $7 \%$ cellulose, standard vitamins, and salt mixture. At the end of the acclimation of one week, the rats were randomly divided into three groups: as control, fructose, and fructose+kefir. Fructose (Danisco Sweeteners OY, Kotka, Finland) was given to the rats as a 20\% solution (w/v) in drinking water ad libitum for 15 weeks. Kefir, which was fermented in our laboratory, was given to the rats once a day as $1 \mathrm{ml}$ per $100 \mathrm{~g}$ of body weight of animal by gastric gavage for the final 6 weeks. The same volume of water was also given to the control and fructose groups by gavage in the same period for sham operation. At the end of the feeding periods, the rats were anesthetized with a mixture of ketamine-xylazine (100 and $10 \mathrm{mg} / \mathrm{kg}$, respectively, i.p.). The 
Akar et al. The inverse association between ANGPTL8 and PI3K-mTOR-PPAR $\gamma$ expressions in adipose tissue of high-fructosefed rats: The modulatory effect of kefir

omental adipose tissues were immediately dissected, blotted dry, and frozen in liquid nitrogen and stored at $-85^{\circ} \mathrm{C}$ for the measurements.

\section{Preparation of kefir}

The kefir grains were obtained from Ankara University, Faculty of Agriculture and used ( $5 \% \mathrm{w} / \mathrm{v}$ ) to inoculate the pasteurized cow's whole milk. The fermentation was carried out at $22^{\circ} \mathrm{C}$ for $24 \mathrm{~h}$. Afterward, the mixture of kefir grain and fermented milk were separated by filtering through a sieve. Kefir was freshly prepared every other day. Kefir grains were stored at $4^{\circ} \mathrm{C}$ until further use. It contained $8.74 \pm 0.46 \mathrm{log}$ CFU/ml of lactic acid bacteria and $4.12 \pm 0.78 \mathrm{log}$ CFU/ml of yeast, not containing acetic acid bacteria. Microbial combination of kefir was determined with a metagenomic approach based on next-generation sequencing technology, as we stated in a very recent study (Akar et al., 2021).

\section{Determination of gene expressions with quantitative real-time polymerase chain reaction (qRT-PCR)}

Total RNAs were isolated from adipose tissue using RNeasy total RNA isolation kit (Qiagen, Venlo, Netherlands), as described according to the manufacturer protocol. After isolation, the amount and the quality of the total RNAs were determined by spectrophotometry and agarose gel electrophoresis. Then, one $\mu \mathrm{g}$ of total RNA was reverse transcribed to cDNA using a commercial first-strand cDNA synthesis kit (Thermo Fisher Scientific, Waltham, MA, USA). Expression levels of angpt/8, pi3k, mtor, ppary, sirtuin1 (sirt1) and nuclear factor erythroid 2-related factor 2 ( $n r f 2$ ) were determined with a real-time quantitative polymerase chain reaction (qRT-PCR, LightCycler480 II, Roche, Basel, Switzerland). To do this, $1 \mu \mathrm{l}$ cDNA, $5 \mu \mathrm{l}$ 2X SYBR Green Master mix (Roche FastStart Universal SYBR Green Master Mix, Roche, Basel, Switzerland), and $2 \mu$ l primer pairs of each (Table 1) at $0.5 \mu \mathrm{M}$ concentrations in a final volume of $10 \mu \mathrm{l}$ were mixed. qRT-PCR was performed as follows: initial denaturation at $95^{\circ} \mathrm{C}$ for $10 \mathrm{~min}$, denaturation at $95^{\circ} \mathrm{C}$ for $10 \mathrm{~s}$, annealing at $58^{\circ} \mathrm{C}$ for $15 \mathrm{~s}$ and extension at $72^{\circ} \mathrm{C}$ for $15 \mathrm{~s}$ with 40 repeated thermal cycles measuring the green fluorescence at the end of each extension step. All reactions were performed in triplicate and the specificity of PCR products was confirmed by melt analysis. The relative expression of genes to internal control glyceraldehyde 3-phosphate dehydrogenase (gapdh) was calculated with the quantification tool provided by LightCycler $^{\circledast} 480$ SW 1.5.1 software.

\section{Measurement of inflammatory parameters in the adi- pose tissue}

The adipose tissue samples were homogenized in $0.1 \mathrm{M}$ phosphate buffer 1:10 (w/v), pH 7.4 and 24,000 cycles/min (Ultra Turrax, IKA Works Inc., USA), and then ultrasonicated at 20,000 cycles/s for 1 min (Dr. Hielscher, Germany). Homogenates were centrifuged at $10,000 \times \mathrm{g}$ and $4^{\circ} \mathrm{C}$ for $15 \mathrm{~min}$, and the supernatants were collected. All the samples were stored at $-85^{\circ} \mathrm{C}$ until analysis. Interleukin (IL)-1 $\beta, \mathrm{IL}-6$, and IL-10 levels in the adipose tissue of rats were measured by using ELISA kits (Cusabio, Houston, TX, USA) according to the manufacturer's instructions.

\section{Statistical analysis}

The results are given as the mean \pm standard error of the mean $(\mathrm{SEM}) ; \mathrm{n}$ is the number of rats. Statistical analyses were performed using one-way ANOVA followed by the Bonferroni post hoc test. Data were evaluated with GraphPad Prism (version 6.0, GraphPad Software, La Jolla, CA, USA). P values smaller than 0.05 were considered as statistically significant.

\section{RESULTS}

\section{Metabolic parameters}

Firstly, we used adipose tissue of the rats from our very recent study (Akar et al., 2021), where we have presented the data with metabolic parameters, including body weight, omental fat mass, plasma levels of glucose, insulin, and triglyceride in rats subjected to high-fructose diet as well as kefir supplementation. Briefly, in that paper (Akar et al., 2021), we reported that the major bacteria strains found in the kefir were L. kefiranofaciens (85.5\%) and L. helveticus (12.5\%), while the most abundant yeast species were Kluyveromyces marxianus (70.4\%) and Saccharomyces mikatae (29.2\%). Regarding metabolic parameters, dietary high-fructose or kefir supplementation did not change the body weight of rats. Importantly, high-fructose intake increased omental fat mass of rats which was markedly reduced by kefir supplementation. High-fructose-induced elevation in plasma glucose was not changed by kefir, but the increase in the insulin level was diminished with kefir. However, dietary fructose-induced augmentation in plasma triglyc-

Table 1. Primer sequences angptl8, pi3k, mtor, ppary, sirt1, nrf2 and internal standard gapdh used for the mRNA expression determination of qRT-PCR.

\begin{tabular}{|c|c|c|c|}
\hline Gene & Forward primer sequence $\left(5^{\prime} \rightarrow 3^{\prime}\right)$ & Reverse primer sequence $\left(3^{\prime} \rightarrow 5^{\prime}\right)$ & $\begin{array}{l}\text { Genbank } \\
\text { accession number }\end{array}$ \\
\hline angptl8 & CCTTTTTGACCAAGCACTGG & AAGTGTCСTCTTCTGCCTGA & NM_001271710.1 \\
\hline pi3k & ATGCAACTGCCTTGCACATT & CGCCTGAAGCTGAGCAACAT & NM_053481.2 \\
\hline mtor & GCAATGGGCACGAGTTTGTT & AGTGTGTTCACCAGGCCAAA & NM_019906.1 \\
\hline ppary & CTCAGGTCAGAGTCGCCCC & GAGAGAGACCTCGTCAGGCT & NM_001145367.1 \\
\hline sirt1 & CGGTCTGTCAGCATCATCTTCC & CGCCTTATCCTCTAGTTCCTGTG & XM_008772947.1 \\
\hline nrf2 & GATTCGTGCACAGCAGCA & GCCAGCTGAACTCCTTAGAC & XM_006234397.2 \\
\hline gapdh & TCCTTGGAGGCCATGTGGGCCAT & TGATGACATCAAGAAGGTGGTGAAG & NM_017008.4 \\
\hline
\end{tabular}


eride was reduced by supplementation of kefir. To investigate possible mechanisms of omental fat accumulation due to the dietary high-fructose and modulatory effect of kefir, we tested the adipose tissue of the same animals in the current study.

High-intake of fructose augmented the gene expression level of angpt/8 in the adipose tissue ( 2.68 fold, $p<0.05$ versus control group). The supplementation of kefir significantly decreased the expression of angpt/8 in the adipose tissue of rats (2.29 fold, p<0.05 versus fructose group; Figure 1a). However, high-fructose intake reduced the expression level of pi3k (5.49 fold, $p<0.05$ versus control group), which was significantly increased by kefir supplementation ( 2.40 fold, $p<0.05$ versus fructose group), in the adipose tissue (Figure $1 \mathrm{~b}$ ). In the adipose tissue, high-fructose intake decreased mtor mRNA expression
(2.75 fold, $\mathrm{p}<0.05$ versus control group), while kefir treatment improved the expression of this gene ( 1.43 fold, $p<0.05$ versus fructose group; Figure 1c). Excess fructose intake suppressed ppary gene expression ( 1.55 fold, $\mathrm{p}<0.05$ versus control group), and kefir supplementation did not show any marked change of ppary expression in the adipose tissue of rats (Figure 1d). On the other hand, mRNA expression levels of sirt1 and nrf2, which are cytoprotective factors, were not altered by fructose or kefir treatment in the adipose tissue of rats (Figure $2 a, b$ ).

High-fructose intake increased the level of proinflammatory cytokine IL-1 $\beta$ (1.66 fold, $p<0.05$ versus control group), which was not improved by kefir supplementation in the adipose tissue of rats (Figure 3a). Also, dietary high-fructose reduced the level of antiinflammatory cytokine IL-10 (1.64 fold, $\mathrm{p}<0.05$
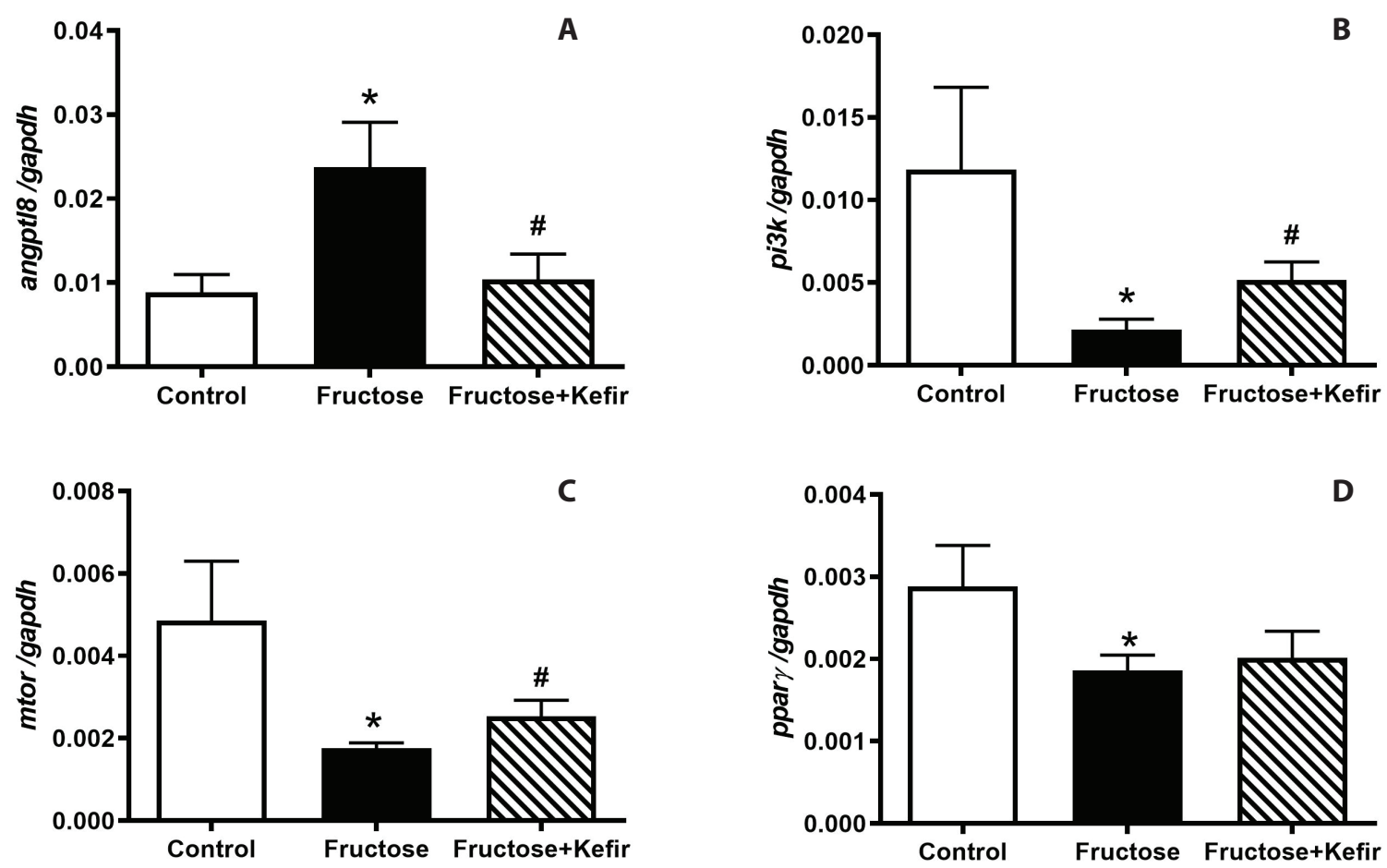

Figure 1. The mRNA expression levels of angpt/8 (A), pi3k (B), mtor (C), and ppary (D) in the adipose tissue of control, fructose, and fructose+kefir groups. Data were normalized using gapdh. Each bar represents the means from at least six rats. ${ }^{*} P<0.05$, significantly different from the control; ${ }^{*} p<0.05$, significantly different from the fructose group.
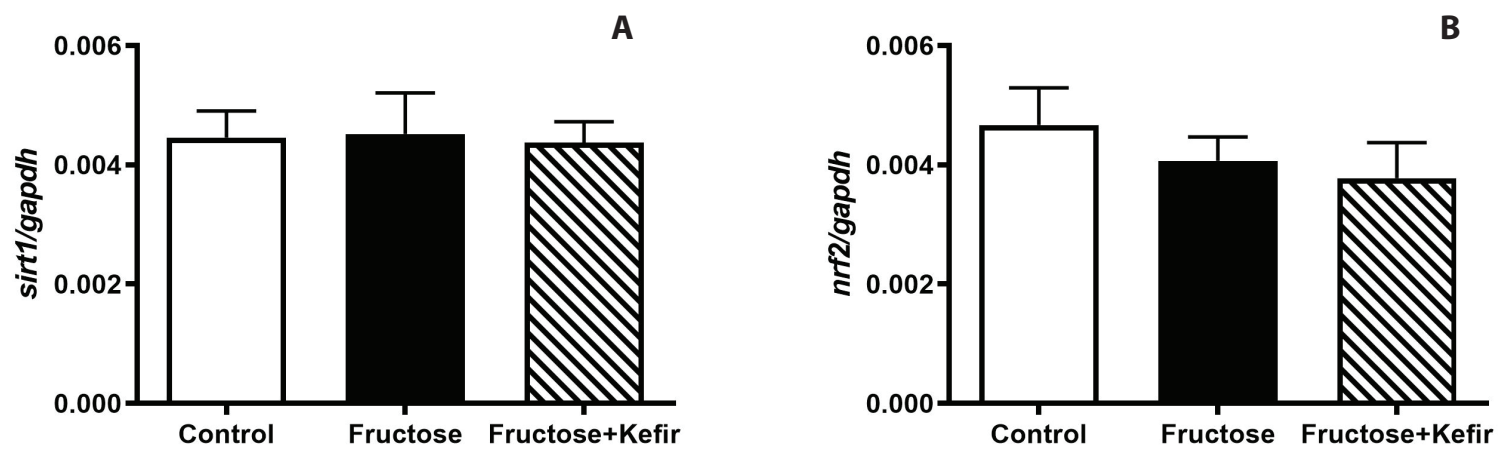

Figure 2. The mRNA expression levels of sirt1 (A) and $n r f 2$ (B) in the adipose tissue of control, fructose, and fructose+kefir groups. Data were normalized using gapdh. Each bar represents the means from at least six rats. 

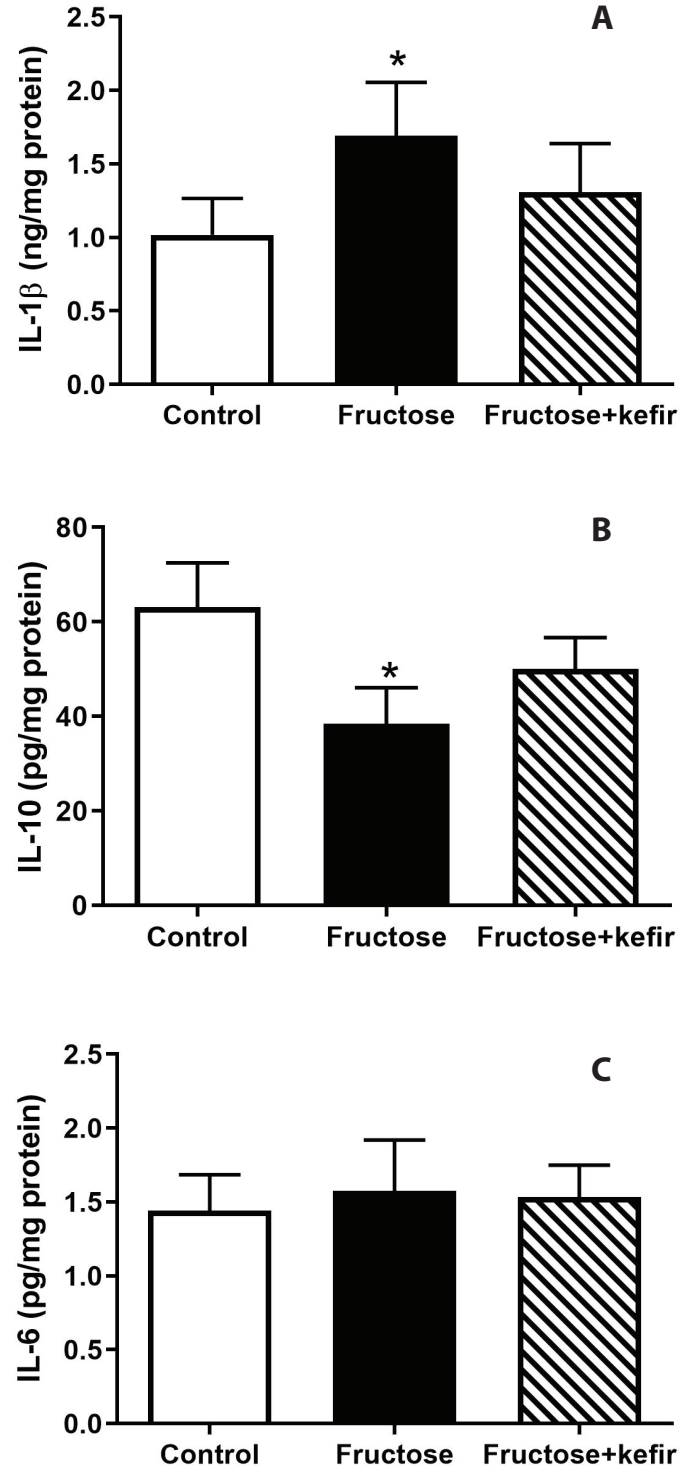

Figure 3. The levels of IL-1 $\beta$ (A), IL-10 (B), and IL-6 (C) in the adipose tissue of control, fructose, and fructose+kefir groups. Each bar represents the means from at least six rats. " $p<0.05$, significantly different from the control.

versus control group) in the adipose tissue, but kefir treatment did not show any regulatory effect on this factor (Figure 3b). Another cytokine IL-6 was not affected by fructose or kefir treatment in the adipose tissue of rats (Figure 3c).

\section{DISCUSSION}

The worldwide high frequency of metabolic syndrome is generally accepted due to excess consumption of sugar and fat in the human diet. Accumulating evidence indicates that high intake of fructose provokes metabolic syndrome manifesting dysfunction of the liver, adipose, and vascular tissue (Hannou et al., 2018; Jensen et al., 2018). In our previous studies, we have reported that oral administration of $20 \%(\mathrm{w} / \mathrm{v})$ fructose causes metabolic syndrome characterized by hypertriglyceridemia, hyperglycemia, hyperinsulinemia, and abdominal fat accumulation leading to dysregulation in vascular, hepatic, renal, intestinal, and testicular functions (Akar et al., 2012, Yildirim et al., 2019; Korkmaz et al., 2019a; Korkmaz et al., 2019b; Sumlu, Bostancı, Sadi, Alçığır, \& Akar, 2020; Akar et al., 2021). In the current study, we have shown that dietary fructose increased expression of angpt/8, but suppressed pi3k, mtor, and ppary mRNAs together with a change in the levels of inflammatory cytokines in the adipose tissue of rats. Kefir supplementation exerted an improving effect on the expression of these genes, except ppary. Thus, we propose that dietary fructose and kefir may reciprocally affect the lipogenesis-related genes in the adipose tissue.

Insulin plays a vital role in the regulation of energy metabolism by inhibiting gluconeogenesis and promoting lipogenesis (Brown \& Goldstein, 2008). In the insulin-resistant state, the hormone loses its ability to reduce glucose production, but paradoxically maintains the lipid synthesis (Brown \& Goldstein, 2008; Li, Brown, \& Goldstein, 2010). In this context, we showed that fructose intake in the long-term period increased abdominal fat mass, expression of genes involved in insulin signaling, despite induction of proinflammatory markers in the adipose tissues from rats (Pektas et al., 2015; Pektas et al., 2016). Therefore, we propose that the upregulation of insulin signaling pathway in adipose tissue leads to increased visceral adiposity together with an inflammatory status (Pektas et al., 2016). We have also demonstrated that abdominal fat accumulation is accompanied by upregulation of lipogenic genes such as srebp$1 \mathrm{c}$ and fasn expression in the adipose tissue of high-fructosefed rats (Akar et al., 2021). Indeed, fructose-induced metabolic disturbance is more likely related to increase in abdominal fat mass, independent of general obesity (Pektas et al., 2015; Akar et al., 2021). The contribution of the other lipogenesis-related genes such as angpt/8, pi3k, mtor and ppary to abdominal fat accumulation in high-fructose-fed rats was not identified.

The studies showed that overexpression of ANGPTL8 in the liver increases circulating triglyceride concentration and causes activation of insulin secretion (Quagliarini et al., 2012; Zhang, 2012; Wang et al., 2013). However, lacking hepatic ANGPTL8 causes low plasma triglyceride levels and decreases delivery of dietary lipids to adipose tissue (Oldoni et al., 2020; Izumi et al., 2018). Basically, insulin decreases circulating triglycerides by also inhibiting adipose tissue lipolysis (Nidhina Haridas et al., 2015). It was also reported that insulin significantly increases ANGPTL8 expression in the 3T3-L1 adipocytes cell line (Ren et al., 2012). Besides, the circulating ANGPTL8 levels were found to be increased in certain metabolic diseases, including type 2 diabetes mellitus (Abu-Farha et al., 2015; Hu et al., 2014; Chen et al., 2016), non-alcoholic fatty liver disease (Lee et al., 2016; García-Monzón et al., 2018), obesity (Fu et al., 2014), and metabolic syndrome (Abu-Farha et al., 2016; Wang et al., 2016). Herein, we demonstrated an upregulation of angpt/8 mRNA expression in samples of abdominal adipose tissue in highfructose-fed rats. In the same protocol, we have very recently reported an increase in plasma insulin and triglyceride levels also in abdominal fat mass alongside upregulation of lipogenic genes srebp-1c and fasn in the adipose tissue (Akar et al., 2021). Overall, it can be evident that abdominal fat accumulation together with hyperinsulinemia and hypertriglyceridemia due to 
dietary high-fructose is associated with increased expression of angpt/8 mRNA and other lipogenic genes, namely srebp-1c and fasn in the adipose tissue.

The gene and protein expression of ANGPTL8 is stimulated by different proinflammatory cytokines such as TNFa and IL-1 in various cell lines. Also, it was observed that there was a correlation between ANGPTL8 level and lipopolysaccharide-induced acute inflammatory response in the different tissues of mice (Zhang et al., 2017). In this study, proinflammatory cytokine IL$1 \beta$ was increased in the adipose tissues of rats fed with highfructose consistent with the results of previous studies (Ma et al., 2013; Pektas et al., 2016). Besides, we also showed that dietary high-fructose leads to low level of IL-10, which is known as an antiinflammatory cytokine, in fat tissue, in agreement with an earlier observation (Barroso et al., 2015). Herein, for the first time, we established that upregulation of angpt/8 is associated with an increase in inflammatory factor, but a decrease in counter regulatory response in adipose tissue. Thus, it can be suggested that there was a correlation between ANGPTL8 and inflammatory factors in adipose tissue in dietary intervention with high-fructose. These findings may be valuable to better understand the role of ANGPTL8 in metabolic syndrome.

In adipose tissue, insulin suppresses lipolysis activating PI3K formation (Okada, Kawano, Sakakibara, Hazeki, \& Ui, 1994). Adipocytes obtained from type 2 diabetic patients showed diminished PI3K activation (Rondinone et al., 1997). Also, expression levels of pi3k and ppary mRNAs were reduced in adipose tissue of mice with high-fat diet-induced insulin resistance (Li, Yu, \& Zhao, 2019). PPARy activation improves hyperglycemia by increasing sensitivity to peripheral insulin, also decreases triglyceride and adipocyte hypertrophy (Yamauchi et al., 2001). Deletion of PPARy in the adipose tissue of mice resulted in marked adipocyte hypertrophy and elevation in plasma triglyceride together with insulin resistance (He et al., 2003). It has been shown that the PPARy signaling through mTOR regulates the differentiation of pre-adipocytes. mTOR deficiency was reported to cause insulin resistance and downregulation of PPARY expression in white adipose tissue of mice (Shan et al., 2016). All these indicated that PI3K, PPAR $y$, and mTOR work together as insulin downstream effectors in the regulation of adipogenesis. In a previous study, we surprisingly detected an upregulation in insulin downstream effectors, including pi3k, mtor, and ppary mRNAs in adipose tissue of rats subjected to fructose intake (10\% fructose in drinking water) in the long-term period of 24 weeks (Pektas et al., 2016). In the present study, expressions of pi3k, mtor, and ppary mRNAs were impaired in the adipose tissue of rats given $20 \%$ fructose solution for 15 weeks. These discrepancies can be attributed to the differences in concentration and duration of fructose given in diet reflecting adaptive and compensatory changes. Taken all together, the increases in angpt/8 expression and inflammatory factor IL-1 $\beta$ level were associated with the impairment in pi3k, mtor, and ppary mRNAs, also anti inflammatory factor IL-10 levels, in the adipose tissue of rats fed with high-fructose. Regarding cytoprotective factors such as sirt1 and nrf2, which could be activated as a compensatory mechanism to counteract inflammation in adipose tissues, we did not measure any change in their genes expression by dietary fructose indicating these factors are not closely related to the process in adipocytes during fructose feeding (Yoshizaki et al., 2009; Schneider \& Chan, 2013).

Recently we and others showed that, kefir supplementation improved the metabolic parameters including plasma triglyceride, and insulin levels as well as omental fat mass in high-fructose-fed rats and metabolic disorders induced by monosodium glutamate (Akar et al., 2021; Rosa et al., 2016). Furthermore, supplementation with L. kefiri, which is one of the probiotic bacteria of kefir, suppressed body weight gain and epididymal adipose tissue expansion in high-fructose-fed mice (Zubiría et al., 2017). Herein, kefir supplementation suppressed the increased angpt/8 mRNA expression in adipose tissue of high-fructose-fed rats. In this line, Tibet kefir intake was shown to reduce plasma triglyceride levels and abdominal fat mass as well as to normalize gene expression of angpt/4 which is an activator of triacylglycerol metabolism (Janssen et al., 2018) in the adipose tissue of high-fat diet-fed rats (Gao et al., 2019). In our previous study, kefir has not normalized the upregulation of lipogenic genes srebp-1c and fasn in the adipose tissue but reduced abdominal fat mass (Akar et al., 2021). Given, improving effect of kefir on abdominal fat accumulation may depend on downregulation of angpt/8 mRNA in adipose tissue of high-fructose-fed rats. Additionally, for the first time, we have found a decrease in pi3k and mtor mRNAs, which are downstream effectors of insulin, in the adipose tissue after kefir supplementation to fructose feeding rats. However, kefir supplementation did not change the decreased ppary mRNA expression in this tissue. Treatment with kefir powder obtained from households in Russia reduced epididymal fat pad weight and PPARY in high-fat diet-induced obese mice (Choi et al., 2017). Notably, lactic acid bacteria strains possessed PPARa/Y agonist activity and ameliorated dyslipidemia in obese mice (Nakamura et al., 2016). More studies are required to elucidate the modulatory effect of kefir on lipogenesis-related genes, including pi3k, mtor, and ppary in adipose tissue.

In conclusion, dietary fructose-activated gene expression of angpt/8, together with the suppression of pi3k, mtor, and ppary mRNAs, showed that there was an inverse association between these two classes of lipogenic genes in adipose tissue of rats fed with high-fructose. These were accompanied by changed inflammatory factors. Kefir supplementation has modulatory effects on fructose-induced changes except for the levels of inflammatory factors and ppary expression. Our findings revealed that dietary fructose and kefir might reciprocally affect the lipogenesis-related genes in the adipose tissue. Further studies are necessary to clarify dietary regulation of lipogenesis in adipose tissue.

Peer-review: Externally peer-reviewed.

Ethics Committee Approval: This study was approved by the Ethical Animal Research Committee of Gazi University (G.Ü.ET-18.018).

Author contributions: Conception/Design of Study- F.A.; Data Acquisition- F.A., C.G., H.B.Ö., M.B.P., H.B.K., A.K., G.S.; Data Analysis/Interpretation-F.A., G.S., C.G., H.B.K.; Drafting Manuscript- F.A., C.G.; Critical Revision of Manuscript-F.A., G.S.; Final Approval and Accountability- F.A., C.G., H.B.Ö., M.B.P., H.B.K., A.K., G.S. 
Conflict of Interest: The authors have no conflict of interest to declare.

Financial Disclosure: This study was supported by Gazi University Research Fund with the grant number BAP 02/2018-14.

\section{REFERENCES}

- $\quad$ Abu-Farha, M., Abubaker, J., Al-Khairi, I., Cherian, P., Noronha, F., Kavalakatt, S., ... Elkum, N. (2016). Circulating angiopoietin-like protein 8 (betatrophin) association with HsCRP and metabolic syndrome. Cardiovascular Diabetology, 15(1), 25.

- $\quad$ Abu-Farha, M., Abubaker, J., Al-Khairi, I., Cherian, P., Noronha, F., Hu, F. B., ... Elkum, N. (2015). Higher plasma betatrophin/ANGPTL8 level in Type 2 Diabetes subjects does not correlate with blood glucose or insulin resistance. Scientific Reports, 5(1), 1-8.

- Akar, F., Uludağ, O., Aydın, A., Aytekin, Y. A., Elbeg, S., Tuzcu, M., \& Sahin, K. (2012). High-fructose corn syrup causes vascular dysfunction associated with metabolic disturbance in rats: protective effect of resveratrol. Food and Chemical Toxicology, 50(6), 2135-2141.

- Akar, F., Sumlu, E., Alçı̆̆ır, M. E., Bostancı, A., \& Sadi, G. (2021). Potential mechanistic pathways underlying intestinal and hepatic effects of kefir in high-fructose-fed rats. Food Research International, 143, 110287. https://doi.org/10.1016/j.foodres.2021.110287

- Barroso, E., Rodríguez-Rodríguez, R., Chacón, M. R., Maymó-Masip, E., Ferrer, L., Salvadó, L., ... Vázquez-Carrera, M. (2015). PPARß/ $\delta$ ameliorates fructose-induced insulin resistance in adipocytes by preventing Nrf2 activation. Biochimica et Biophysica Acta (BBA)Molecular Basis of Disease, 1852(5), 1049-1058.

- Bastard, J. P., Maachi, M., Lagathu, C., Kim, M. J., Caron, M., Vidal, H. ... Feve, B. (2006). Recent advances in the relationship between obesity, inflammation, and insulin resistance. European Cytokine Network, 17(1), 4-12.

- $\quad$ Brown, M. S., \& Goldstein, J. L. (2008). Selective versus total insulin resistance: a pathogenic paradox. Cell Metabolism, 7(2), 95-96.

- Carbone, C., Piro, G., Merz, V., Simionato, F., Santoro, R., Zecchetto, C., Tortora, G., \& Melisi, D. (2018). Angiopoietin-Like Proteins in Angiogenesis, Inflammation and Cancer. International Journal of Molecular Sciences, 19(2), 431.

- Chen, C. C., Susanto, H., Chuang, W. H., Liu, T. Y., \& Wang, C. H. (2016). Higher serum betatrophin level in type 2 diabetes subjects is associated with urinary albumin excretion and renal function. Cardiovascular Diabetology, 15(1), 1-9.

- Chen, H. L., Tsai, T. C., Tsai, Y. C., Liao, J. W., Yen, C. C., \& Chen, C. M. (2016). Kefir peptides prevent high-fructose corn syrup-induced non-alcoholic fatty liver disease in a murine model by modulation of inflammation and the JAK2 signaling pathway. Nutrition \& Diabetes, 6(12), e237-e237.

- Choi, J. W., Kang, H. W., Lim, W. C., Kim, M. K., Lee, I. Y., \& Cho, H. Y. (2017). Kefir prevented excess fat accumulation in diet-induced obese mice. Bioscience, Biotechnology, and Biochemistry, 81(5), 958-965.

- $\quad F u$, Z., Berhane, F., Fite, A., Seyoum, B., Abou-Samra, A. B., \& Zhang, R. (2014). Elevated circulating lipasin/betatrophin in human type 2 diabetes and obesity. Scientific Reports, 4(1), 1-5.

- $\quad$ Gao, J., Ding, G., Li, Q., Gong, L., Huang, J., \& Sang, Y. (2019). Tibet kefir milk decreases fat deposition by regulating the gut microbiota and gene expression of Lpl and Angpt/4 in high fat diet-fed rats. Food Research International, 121, 278-287.

- García-Monzón, C., Petrov, P. D., Rey, E., Marañón, P., del PozoMaroto, E., Guzmán, C., ... Miquilena-Colina, M. E. (2018). Angiopoietin-like protein 8 is a novel vitamin d receptor target gene involved in nonalcoholic fatty liver pathogenesis. The American Journal of Pathology, 188(12), 2800-2810.
Han, C., Wei, S., He, F., Liu, D., Wan, H., Liu, H., ... Xu, F. (2015). The regulation of lipid deposition by insulin in goose liver cells is mediated by the PI3K-AKT-mTOR signaling pathway. PloS One, 10(5), e0098759.

Hannou, S. A., Haslam, D. E., McKeown, N. M., \& Herman, M. A. (2018). Fructose metabolism and metabolic disease. The Journal of Clinical Investigation, 128(2), 545-555.

He, W., Barak, Y., Hevener, A., Olson, P., Liao, D., Le, J., ... Evans, R. M. (2003). Adipose-specific peroxisome proliferator-activated receptor $\gamma$ knockout causes insulin resistance in fat and liver but not in muscle. Proceedings of the National Academy of Sciences, 100(26), 15712-15717.

Hu, H., Sun, W., Yu, S., Hong, X., Qian, W., Tang, B., ... Zhou, L. (2014). Increased circulating levels of betatrophin in newly diagnosed type 2 diabetic patients. Diabetes Care, 37(10), 2718-2722.

Huang, X., Liu, G., Guo, J., \& Su, Z. (2018). The PI3K/AKT pathway in obesity and type 2 diabetes. International Journal of Biological Sciences, 14(11), 1483.

Izumi, R., Kusakabe, T., Noguchi, M., Iwakura, H., Tanaka, T., Miyazawa, T., ... Nakao, K. (2018). CRISPR/Cas9-mediated Angptl8 knockout suppresses plasma triglyceride concentrations and adiposity in rats. Journal of Lipid Research, 59(9), 1575-1585.

Janssen, A. W., Katiraei, S., Bartosinska, B., Eberhard, D., van Dijk, K. W., \& Kersten, S. (2018). Loss of angiopoietin-like 4 (ANGPTL4) in mice with diet-induced obesity uncouples visceral obesity from glucose intolerance partly via the gut microbiota. Diabetologia, 61(6), 1447-1458.

Jensen, T., Abdelmalek, M. F., Sullivan, S., Nadeau, K. J., Green, M., Roncal, C., ... Tolan, D. R. (2018). Fructose and sugar: A major mediator of non-alcoholic fatty liver disease. Journal of Hepatology, 68(5), 1063-1075.

Kim, D. H., Jeong, D., Kim, H., \& Seo, K. H. (2019). Modern perspectives on the health benefits of kefir in next generation sequencing era: Improvement of the host gut microbiota. Critical Reviews in Food Science and Nutrition, 59(11), 1782-1793.

Korkmaz, O. A., Sumlu, E., Koca, H. B., Pektas, M. B., Kocabas, A., Sadi, G., \& Akar, F. (2019a). Effects of Lactobacillus plantarum and Lactobacillus helveticus on renal insulin signaling, inflammatory markers, and glucose transporters in high-fructose-fed rats. Medicina, 55(5), 207. Korkmaz, O. A., Sadi, G., Kocabaş, A., Yıldırım, O. G., Sumlu, E., Koca, H. B., ... Akar F. (2019b). Lactobacillus helveticus and Lactobacillus plantarum modulate renal antioxidant status in a rat model of fructose-induced metabolic syndrome. Archives of Biological Sciences, 71 (2), 265-273.

Laplante, M., \& Sabatini, D. M. (2012). mTOR signaling in growth control and disease. Cell, 149(2), 274-293.

Lee, Y. H., Lee, S. G., Lee, C. J., Kim, S. H., Song, Y. M., Yoon, M. R., ... Lee, H. C. (2016). Association between betatrophin/ANGPTL8 and non-alcoholic fatty liver disease: animal and human studies. Scientific Reports, 6(1), 1-12.

Li, H., Yu, L., \& Zhao, C. (2019). Dioscin attenuates high-fat diet-induced insulin resistance of adipose tissue through the IRS-1/PI3K Akt signaling pathway. Molecular Medicine Reports, 19(2), 1230-1237. Li, S., Brown, M. S., \& Goldstein, J. L. (2010). Bifurcation of insulin signaling pathway in rat liver: $\mathrm{mTORC1}$ required for stimulation of lipogenesis, but not inhibition of gluconeogenesis. Proceedings of the National Academy of Sciences, 107(8), 3441-3446.

- Ma, X., Lin, L., Yue, J., Pradhan, G., Qin, G., Minze, L. J., ... Sun, Y. (2013). Ghrelin receptor regulates HFCS-induced adipose inflammation and insulin resistance. Nutrition \& Diabetes, 3(12), e99-e99. Nakamura, F., Ishida, Y., Sawada, D., Ashida, N., Sugawara, T., Sakai, M., ... Fujiwara, S. (2016). Fragmented lactic Acid bacterial cells activate peroxisome proliferator-activated receptors and ameliorate Dyslipidemia in obese mice. Journal of Agricultural and Food Chemistry, 64(12), 2549-2559. 
- $\quad$ Nidhina Haridas, P. A., Soronen, J., Sädevirta, S., Mysore, R., Quagliarini, F., Pasternack, A., ... Fischer-Posovszky, P. (2015). Regulation of angiopoietin-like proteins (ANGPTLs) 3 and 8 by insulin. The Journal of Clinical Endocrinology \& Metabolism, 100(10), E1299-E1307.

- $\quad$ Okada, T., Kawano, Y., Sakakibara, T., Hazeki, O., \& Ui, M. (1994). Essential role of phosphatidylinositol 3-kinase in insulin-induced glucose transport and antilipolysis in rat adipocytes. Studies with a selective inhibitor wortmannin. Journal of Biological Chemistry, 269(5), 3568-3573.

- Oldoni, F., Cheng, H., Banfi, S., Gusarova, V., Cohen, J. C., \& Hobbs, H. H. (2020). ANGPTL8 has both endocrine and autocrine effects on substrate utilization. JCl Insight, 5(17).

- Pektas, M. B., Sadi, G., \& Akar, F. (2015). Long-term dietary fructose causes gender-different metabolic and vascular dysfunction in rats: modulatory effects of resveratrol. Cellular Physiology and Biochemistry, 37(4), 1407-1420.

- Pektas, M. B., Koca, H. B., Sadi, G., \& Akar, F. (2016). Dietary fructose activates insulin signaling and inflammation in adipose tissue: Modulatory role of resveratrol. BioMed Research International, 2016(8014252), 1-10.

- Quagliarini, F., Wang, Y., Kozlitina, J., Grishin, N. V., Hyde, R., Boerwinkle, E., ... Hobbs, H. H. (2012). Atypical angiopoietin-like protein that regulates ANGPTL3. Proceedings of the National Academy of Sciences, 109(48), 19751-19756.

- Ren, G., Kim, J. Y., \& Smas, C. M. (2012). Identification of RIFL, a novel adipocyte-enriched insulin target gene with a role in lipid metabolism. American Journal of Physiology-Endocrinology and Metabolism, 303(3), E334-E351.

- Rondinone, C. M., Wang, L. M., Lonnroth, P., Wesslau, C., Pierce, J. H., \& Smith, U. (1997). Insulin receptor substrate (IRS) 1 is reduced and IRS-2 is the main docking protein for phosphatidylinositol 3-kinase in adipocytes from subjects with non-insulin-dependent diabetes mellitus. Proceedings of the National Academy of Sciences, 94(8), 4171-4175.

- Rosa, D. D., Dias, M. M., Grześkowiak, Ł. M., Reis, S. A., Conceição, L. L., \& Maria do Carmo, G. P. (2017). Milk kefir: nutritional, microbiological and health benefits. Nutrition Research Reviews, 30(1), 82-96.

- Rosa, D. D., Grześkowiak, Ł. M., Ferreira, C. L., Fonseca, A. C. M., Reis, S. A., Dias, M. M., ... Machado, A. B. (2016). Kefir reduces insulin resistance and inflammatory cytokine expression in an animal model of metabolic syndrome. Food \& Function, 7(8), 3390-3401.

- Sakaue, H., Ogawa, W., Matsumoto, M., Kuroda, S., Takata, M., Sugimoto, T., ... Kasuga, M. (1998). Posttranscriptional control of adipocyte differentiation through activation of phosphoinositide 3-kinase. Journal of Biological Chemistry, 273(44), 28945-28952.

- $\quad$ Scherer, P. E. (2006). Adipose tissue: from lipid storage compartment to endocrine organ. Diabetes, 55(6), 1537-1545.

- Schneider, K. S., \& Chan, J. Y. (2013). Emerging role of Nrf2 in adipocytes and adipose biology. Advances in Nutrition, 4(1), 62-66.
Shan, T., Zhang, P., Jiang, Q., Xiong, Y., Wang, Y., \& Kuang, S. (2016). Adipocyte-specific deletion of mTOR inhibits adipose tissue development and causes insulin resistance in mice. Diabetologia, 59(9), 1995-2004.

- Sumlu, E., Bostancı, A., Sadi, G., Alçığır, M. E., \& Akar, F. (2020). Lactobacillus plantarum improves lipogenesis and IRS-1/AKT/eNOS signalling pathway in the liver of high-fructose-fed rats. Archives of Physiology and Biochemistry, 1-9.

- Wang, D., \& Sul, H. S. (1998). Insulin stimulation of the fatty acid synthase promoter is mediated by the phosphatidylinositol 3-kinase pathway: involvement of protein kinase B/Akt. Journal of Biological Chemistry, 273(39), 25420-25426.

Wang, H., Lai, Y., Han, C., Liu, A., Fan, C., Wang, H., ... Shan, Z. (2016). The effects of serum ANGPTL8/betatrophin on the risk of developing the metabolic syndrome-a prospective study. Scientific Reports, 6(1), 1-8.

Wang, Y., Quagliarini, F., Gusarova, V., Gromada, J., Valenzuela, D. M., Cohen, J. C., \& Hobbs, H. H. (2013). Mice lacking ANGPTL8 (Betatrophin) manifest disrupted triglyceride metabolism without impaired glucose homeostasis. Proceedings of the National Academy of Sciences, 110(40), 16109-16114.

- $\quad$ Yamauchi, T., Kamon, J., Waki, H., Murakami, K., Motojima, K., Komeda, K., ... Kadowaki, T. (2001). The mechanisms by which both heterozygous peroxisome proliferator-activated receptor $\gamma$ (PPAR $\gamma$ ) deficiency and PPARy agonist improve insulin resistance. Journal of Biological Chemistry, 276(44), 41245-41254.

- Yildirim, O. G., Sumlu, E., Aslan, E., Koca, H. B., Pektas, M. B., Sadi, G., \& Akar, F. (2019). High-fructose in drinking water initiates activation of inflammatory cytokines and testicular degeneration in rat. Toxicology Mechanisms and Methods, 29(3), 224-232.

- Yoshizaki, T., Milne, J. C., Imamura, T., Schenk, S., Sonoda, N., Babendure, J. L., ... Olefsky, J. M. (2009). SIRT1 exerts anti-inflammatory effects and improves insulin sensitivity in adipocytes. Molecular and Cellular Biology, 29(5), 1363-1374.

- Zhang, H. H., Huang, J., Düvel, K., Boback, B., Wu, S., Squillace, R. M., ... Manning, B. D. (2009). Insulin stimulates adipogenesis through the Akt-TSC2-mTORC1 pathway. PloS one, 4(7), e6189.

- Zhang, R. (2012). Lipasin, a novel nutritionally-regulated liver-enriched factor that regulates serum triglyceride levels. Biochemical and Biophysical Research Communications, 424(4), 786-792.

Zhang, Y., Guo, X., Yan, W., Chen, Y., Ke, M., Cheng, C., ... Wang, S. (2017). ANGPTL8 negatively regulates NF-KB activation by facilitating selective autophagic degradation of IKKY. Nature Communications, 8(1), 1-13.

Zubiría, M. G., Gambaro, S. E., Rey, M. A., Carasi, P., Serradell, M. D. L. Á., \& Giovambattista, A. (2017). Deleterious metabolic effects of high fructose intake: the preventive effect of Lactobacillus kefiri administration. Nutrients, 9(5), 470. 